\title{
Corrigendum: MacroH2A histone variants act as a barrier upon reprogramming towards pluripotency
}

Alexandre Gaspar-Maia, Zulekha A. Qadeer, Dan Hasson, Kajan Ratnakumar, N. Adrian Leu, Gary Leroy, Shichong Liu, Carl Costanzi, David Valle-Garcia, Christoph Schaniel, Ihor Lemischka, Benjamin Garcia, John R. Pehrson \& Emily Bernstein

Nature Communications 4:1565 doi: 10.1038/ncomms2582 (2013); Published 5 Mar 2013; Updated 29 Aug 2013

An image in Supplementary Fig. S9b in this Article, reporting $\alpha \mathrm{H} 3 \mathrm{~K} 27 \mathrm{me} 3 / \mathrm{DAPI}$ immunofluorescence in iPS cells from the 'dKO' group, was inadvertently duplicated from the 'wt' group. The correct version of the figure appears below.

a

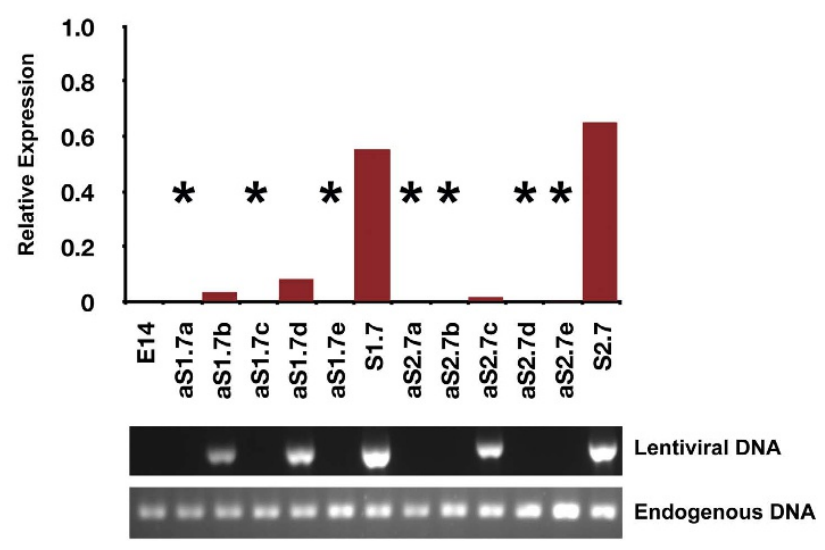

b
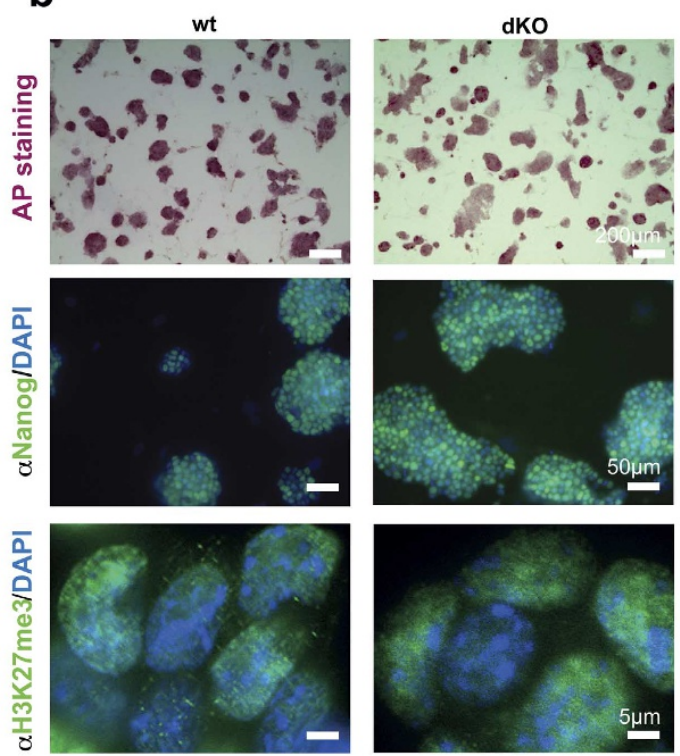